\title{
Residual Stress and Deformation of Consolidated Structure Obtained by Layered Manufacturing Process*
}

\author{
Mohd Sanusi ABDUL AZIZ**, Tatsuaki FURUMOTO***, \\ Kazuhiro KURIYAMA***, Shigeki TAKAGO****, Satoshi ABE*****, \\ Akira HOSOKAWA*** and Takashi UEDA*** \\ ** Kanazawa University, Kakuma-machi, Kanazawa, Ishikawa 920-1192, Japan and \\ Universiti Teknikal Malaysia Melaka, Hang Tuah Jaya, 76100 Durian Tunggal, Melaka, Malaysia \\ E-mail: msanusi@stu.kanazawa-u.ac.jp \\ *** Kanazawa University, Kakuma-machi, Kanazawa, Ishikawa 920-1192, Japan \\ **** Industrial Research Institute of Ishikawa, 2-1, Kuratsuki, Kanazawa, Ishikawa, 920-8203 Japan \\ ***** Panasonic Corporation Eco Solutions Company, 1048, Kadoma, Osaka, 571-8686 Japan
}

\begin{abstract}
This study investigates the residual stress and deformation induced in a consolidated structure obtained through a layered manufacturing process. In this research, temperature and dynamic stress induced in the substrate during a selective laser melting (SLM) process were measured to investigate the influence of laser irradiation conditions on the development of residual stress and deformation in the consolidated structure. The stress was measured using a strain gauge that was attached on the bottom face of the substrate, whereas the temperature was measured using a thermocouple inserted in the substrate. The influences of the substrate height, consolidated structure height, and laser scanning pattern on the deformation and residual stress also were investigated experimentally. Additionally, the effects of different materials used as the substrate on deformation were investigated. It was found that during the laser consolidation process, temperature changes in the substrate caused repeated thermal expansion and shrinkage within the substrate, producing internal stress at the completion of the laser consolidation process. The stress that was induced in the substrate corresponds to the deformation result. Residual stress at the top of the consolidated structure increased whereas residual stress at the bottom of substrate decreased as the height of the consolidated structure increased. However, less deformation occurred when using stainless steel as the substrate.
\end{abstract}

Key words: Layered Manufacturing, Selective Laser Melting, Residual Stress, Deformation, Carbon Steel, Stainless Steel

\section{Introduction}

Recently, with the diversification of market needs, product life cycles have become shorter, requiring manufacturing industries to reduce costs and shorten production development times. In the late 1980s, as the processing capabilities of personal computers improved significantly and three-dimensional (3D) computer-aided design (CAD) and computer-aided manufacturing (CAM) systems grew in popularity, concurrent engineering ${ }^{(1)}$ through the sharing of CAD data was proposed and became an established production method $^{(2)}$. The layered manufacturing process, however, can reduce production

${ }^{*}$ Received 6 Dec., 2012 (No. 12-0499) [DOI: 10.1299/jamdsm.7.244]

Copyright $\odot 2013$ by JSME 
development time significantly. Layered manufacturing is a process in which objects are constructed through the sequential deposition of material layers. 3D CAD data are converted into thin layers of cross-sectional data, a laser beam is used to embody the cross-section design, and the part is built up layer by layer ${ }^{(3)}$. This method can be classified as stereolithography, powder sintering, and others according to the material used ${ }^{(4)}$. During its early development, because of material limitations, the layered manufacturing method was primarily used for rapid prototyping (RP) to verify the shape of the $3 \mathrm{D}$ model. However, in recent years, methods of rapid manufacturing (RM) and rapid tooling (RT) have gained attention ${ }^{(5)}$. RM is a method for producing a product directly using the same material powder as in the actual product; RT is a method for producing a mold directly. Moreover, to improve the surface roughness of the fabricated structure, a hybrid machine that combines the laser consolidation and milling processes and produces injection molding with high accuracy has been developed and practically applied ${ }^{(6)}$.

In the selective laser melting (SLM) process using metal powder, a thin layer of metal powder is deposited on a sandblasted substrate and a laser beam is irradiated on the surface of the deposited powder according to the CAD data. As the laser beam irradiates the deposited metal powder, the powder melts, followed by the cohesion and solidification of the molten metal. During laser irradiation, the temperature of the irradiated area is heated suddenly to more than $1500{ }^{\circ} \mathrm{C}^{(7)}$, and when the laser moves from the irradiated area, the area cools rapidly. After sintering of one layer is finished, the pre-solidified layer undergoes the melting, cohesion, and solidification processes during the laser consolidation of the next layer. These processes are repeated until the final shape is obtained. Therefore, the internal stress within the consolidated structure is complex, and it induces residual stress within the consolidated structure and leads to deformation and dimensional changes ${ }^{(8)(9)}$. Until now, problematic deformation and dimensional changes have been suppressed through countermeasures such as increasing the stiffness of the substrate by increasing its thickness ${ }^{(10)}$ and reducing the thermal gradient by random laser scanning ${ }^{(11)}$, although these steps are symptomatic treatments. A method for remedying the cause of the residual stress induced within the consolidated structure has not yet been proposed.

Previous authors have measured the residual stress within the consolidated structure obtained through layered manufacturing and investigated the relationship between laser scanning and substrate conditions and the residual stress ${ }^{(10)(12)}$. Understanding the development of residual stress and deformation is important for reducing the residual stress and the deformation within the consolidated structure. Therefore, in this research, in-process monitoring of temperature and stress at the substrate was proposed to investigate the temperature and stress behavior during the laser consolidation process. Additionally, the influences of different consolidation conditions such as the laser scanning pattern, substrate height, consolidated structure height, and types of substrate material on residual stress and the deformation of consolidated structure were investigated. Indirectly, these results could lead to methods for reducing residual stress and the deformation of consolidated structures.

\section{Properties of consolidated structure}

\subsection{Layered manufacturing process}

A milling-combined laser consolidation machine (Matsuura Machinery Corp.: LUMEX 25C) was used to prepare the experimental samples. The layered manufacturing process used was the selective laser melting process, which is illustrated in Fig. 1; the laser consolidation conditions are summarized in Table 1. In the process, the substrate that is used as the consolidation base is first sandblasted with $\# 45$ average-size alumina abrasive grain 
to improve the wetting property of the melted powder ${ }^{(13)}$. The system consists of a powder table, a forming table, a recoater blade, and a Yb:fiber laser (IPG Photonic Corp.: YLR-SM). First, a 50- $\mu \mathrm{m}$-thick layer of metal powder is deposited on the substrate using the recoater blade. Then, in accordance with the $3 \mathrm{D}$ CAD data layers, the laser beam irradiates and selectively consolidates each layer of the deposited metal powder. A $94 \mu \mathrm{m}$ laser beam is used at the focus position. These processes are repeated until the complete structure is created. The laser consolidation process is performed in a nitrogen atmosphere at room temperature to prevent oxidization.
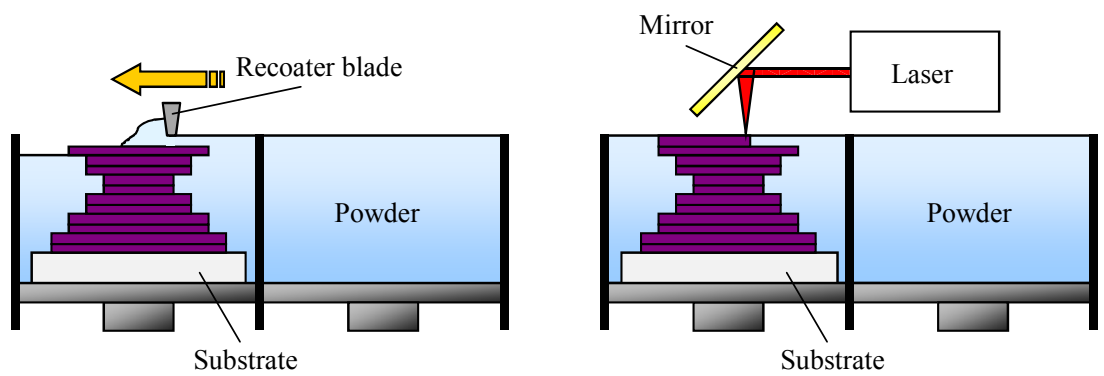

Fig. 1 Selective laser melting process of metal powder

Table 1 Laser consolidation conditions

\begin{tabular}{ll}
\hline Laser type & Yb:fiber $(\mathrm{CW})$ \\
Wavelength & $\lambda=1070 \mathrm{~nm}$ \\
Laser beam diameter & $\phi=94 \mu \mathrm{m}$ \\
Laser power & $P=200 \mathrm{~W}$ \\
Laser scanning speed & $F=222,444 \mathrm{~mm} / \mathrm{s}$ \\
\hline
\end{tabular}

Properties of the metal powder are described in Table 2. It is a mixture of $70 \%$ chromium molybdenum steel powder, $20 \%$ copper alloy powder, and $10 \%$ nickel powder by weight, with a mean diameter of $25 \mu \mathrm{m}$. During the laser consolidation process, metal powder is deposited under the action of gravity only. The bulk density of metal powder is $4190 \mathrm{~kg} / \mathrm{m}^{3}$, representing about $50 \%$ of the true density value ${ }^{(14)}$.

\begin{tabular}{ll}
\multicolumn{1}{c}{ Table 2 Specification of metal powder } \\
\hline Material & $\begin{array}{l}\mathrm{SCM}, \mathrm{Cu}, \mathrm{Ni} \\
\text { Shape }\end{array}$ \\
Particle mean diameter & $d=25 \mu \mathrm{m}$ \\
Bulk density & $\rho=4190 \mathrm{~kg} / \mathrm{m}^{3}$ \\
Absorption ratio & $A_{\mathrm{r}}=25 \%$ \\
Thermal conductivity & $T_{\mathrm{k}}=0.14 \mathrm{~W} / \mathrm{m} \cdot \mathrm{K}$
\end{tabular}

\subsection{Properties of consolidated structure}

Table 3 summarizes the physical properties of the consolidated structure obtained through the layered manufacturing process. The hardness was measured using a micro-hardness tester (Akashi Corp.: HM-101); the thermal conductivity, using a standard 
laser-flash thermal-constant analyzer (ULVAC Tech. Inc.: TC-7000); and the coefficient of thermal expansion, using a differential scanning calorimeter (Rigaku Corp.: DSC 8270). The bulk density was determined by measuring the mass and volume of the consolidated structure using an electron analytical balance (Shimadzu Corp.: AUX220). As shown in Table 3, the hardness of the consolidated structure is $275 \mathrm{HV}$. The hardness of the consolidated structure is smaller than that of the main material in the solid state, owing to the pores and partial melting that occurs during the laser consolidation process ${ }^{(15)}$. The density of the consolidated structure is $7680 \mathrm{~kg} / \mathrm{m}^{3}$, and the thermal conductivity is 8.0 $\mathrm{W} / \mathrm{m} \cdot \mathrm{K}$, which is much smaller than the value in the solid state of the main material. Furthermore, the coefficient of thermal expansion is $7.6 \times 10^{-6} \mathrm{~K}^{-1}$.

Table 3 Properties of consolidated structure

\begin{tabular}{ll}
\hline Hardness & $H=275 \mathrm{HV}$ \\
Bulk density & $\rho=7680 \mathrm{~kg} / \mathrm{m}^{3}$ \\
Thermal conductivity & $k_{\mathrm{m}}=8.0 \mathrm{~W} / \mathrm{m} \cdot \mathrm{K}$ \\
Coefficient of thermal expansion & $\alpha=7.6 \times 10^{-6} \mathrm{~K}^{-1}$ \\
Melting point & $M=1573 \mathrm{~K}$ \\
\hline
\end{tabular}

\section{Experimental procedure}

\subsection{Test sample}

The test sample used in this research is illustrated in Fig. 2, and the dimensions are described in Table 4. As shown in the table, the substrate used as the consolidation platform is composed of carbon steel (AISI 1050) and stainless steel (AISI 304) with height $\left(h_{\mathrm{s}}\right)$ ranging from 5 to $30 \mathrm{~mm}$. The plane size of the substrate is constant at $49 \times 9 \mathrm{~mm}$, whereas the plane size of the consolidated structure, which is built at the center of the substrate, is 45 $\times 5 \mathrm{~mm}$. The thickness of each layer of the deposited metal powder is constant at $50 \mu \mathrm{m}$, and the height of the consolidated structure $\left(h_{\mathrm{c}}\right)$ varies from 1 to $30 \mathrm{~mm}$. Three laser scanning patterns were used in this research to produce the consolidated structure. A schematic illustration of the top view of the laser scanning patterns is shown in Fig. 3. For all layers, laser scanning along only the $\mathrm{X}$-axis is identified as $\mathrm{X}-\mathrm{X}$, and along only the $\mathrm{y}$-axis, as $\mathrm{Y}-\mathrm{Y}$; shifting laser scanning along the $\mathrm{X}$-axis and $\mathrm{y}$-axis after one layer is identified as $\mathrm{X}-\mathrm{Y}$. These three patterns use raster scanning.

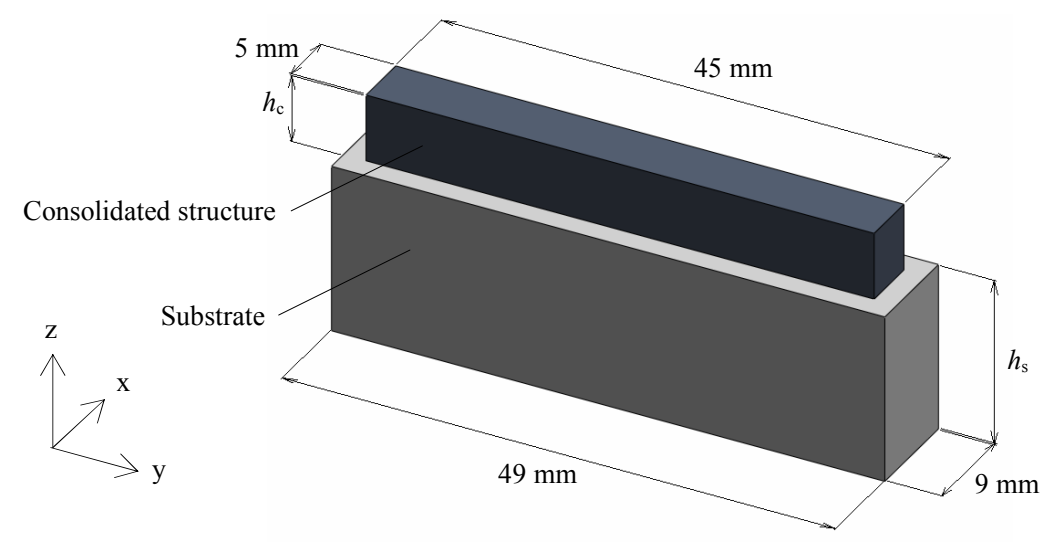

Fig. 2 Illustration of test sample 
Table 4 Dimensions of test sample

\begin{tabular}{ll}
\hline Substrate material & $\begin{array}{l}\text { Carbon steel (AISI 1050), } \\
\text { Stainless steel (AISI 304) }\end{array}$ \\
Plane size (length $\times$ width) & $49 \times 9 \mathrm{~mm}$ \\
Height & $h_{s}=5-30 \mathrm{~mm}$ \\
\hline Consolidated structure & \\
Plane size (length $\times$ width) & $45 \times 5 \mathrm{~mm}$ \\
Height & $h_{\mathrm{c}}=1-30 \mathrm{~mm}$ \\
\hline
\end{tabular}

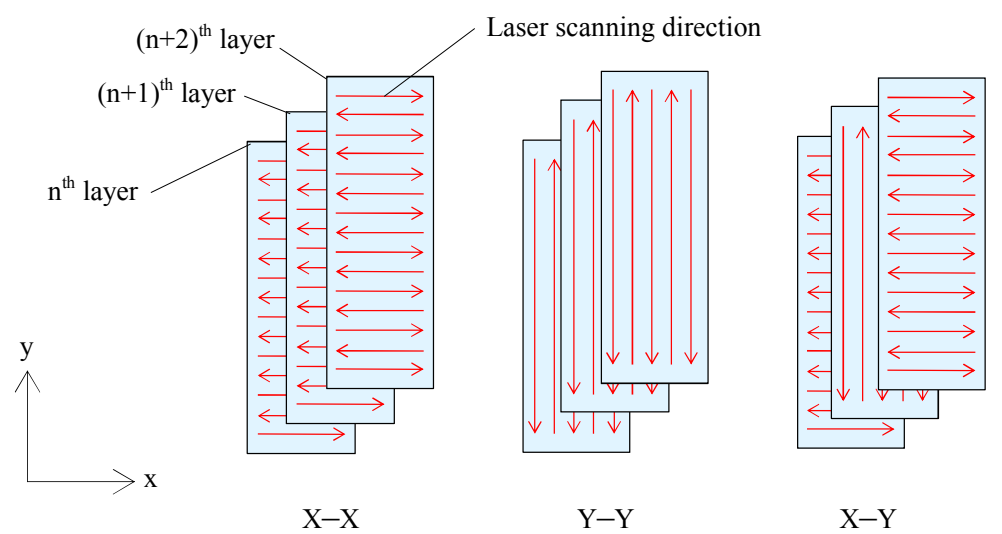

Fig. 3 Variation of laser scanning patterns

\subsection{Measurement of temperature and stress}

To measure temperature and stress in the substrate during the laser consolidation process, thermocouples and strain gauges are attached at the substrate positions specified in Fig. 4. The specifications of the thermocouples and strain gauges used in this experiment are described in Table 5. Type $\mathrm{K}$ sheathed thermocouples (MISUMI Corp.: MSND1.6-50) were used to measure the temperature; these were located at three different positions, denoted by T1, T2, and T3 in the figure. The strain gauges (Kyowa Elec. Inst. Co., Ltd.: KFG-2-120-C1-11) were attached just below the thermocouples at the bottom face of the substrate, and are indicated by S1, S2, and S3. Output voltages of the thermocouples and the strain changes during the laser consolidation process were recorded using a digital oscilloscope, and the temperature and stress were calculated from these values.

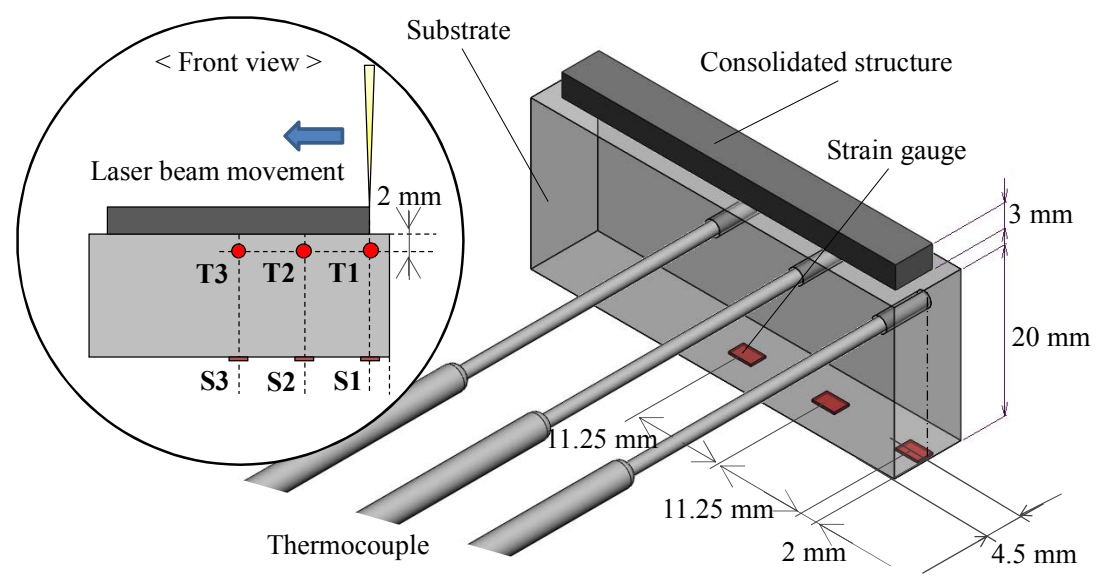

Fig. 4 Arrangement for measuring temperature and stress during the laser consolidation process 
Table 5 Specification of strain gauge and thermocouple

\begin{tabular}{ll}
\hline Strain gauge & KFG-2-120-C1-11 \\
Gauge length & $L=2 \mathrm{~mm}$ \\
Resistance & $R=120 \Omega$ \\
\hline Thermocouple & Type K \\
Outer diameter of sheath & $1.6 \mathrm{~mm}$ \\
Sheath length & $50 \mathrm{~mm}$ \\
\hline
\end{tabular}

\subsection{Measurement of deformation and residual stress}

Deformation of the consolidated structure can be measured using a CCD laser displacement sensor (Keyence Corp.: LK-080) by scanning the bottom face profile of the substrate. As shown in Fig. 5, the deformation height, $h_{\mathrm{d}}$, is determined by measuring the maximum height from the curvature profile of the substrate's bottom face. In addition, residual stress at the surface of the consolidated structure and residual stress at the bottom face of the substrate were measured using an $\mathrm{x}$-ray diffraction stress measurement device (Rigaku Corp.: PSPC-MSF) ${ }^{(16)}$. Table 6 shows the $\mathrm{x}$-ray diffraction conditions. In this experiment, $\mathrm{x}$-rays with a wavelength of $0.229 \mathrm{~nm}$ were applied at the sample surface and, using the ISO-inclination method, the $\gamma-\mathrm{Fe}(220)$ diffraction (for the surface of the consolidated structure) and $\alpha$ - $\mathrm{Fe}(211)$ diffraction (for the bottom face of the substrate) were measured. The peak position used for the x-ray diffraction stress measurement was the full width of half maximum (FWHM) middle point, which was determined using a computer. Moreover, the fixed $\psi_{0}$ method was employed for the ganiometer and a range of angles between the normal of the diffracting plane and the normal of the sample $\left(\psi=0-45^{\circ}\right)$ was used in the measurement. Furthermore, to reduce measurement error due to the surface roughness of the sample, a 4-mm-wide collimator beam was used at the surface of the consolidated structure and a beam of $2 \mathrm{~mm}$ in diameter was used for the bottom face of the substrate. Because the grain size of stainless steel is high, it is necessary to increase the diameter of the collimator.

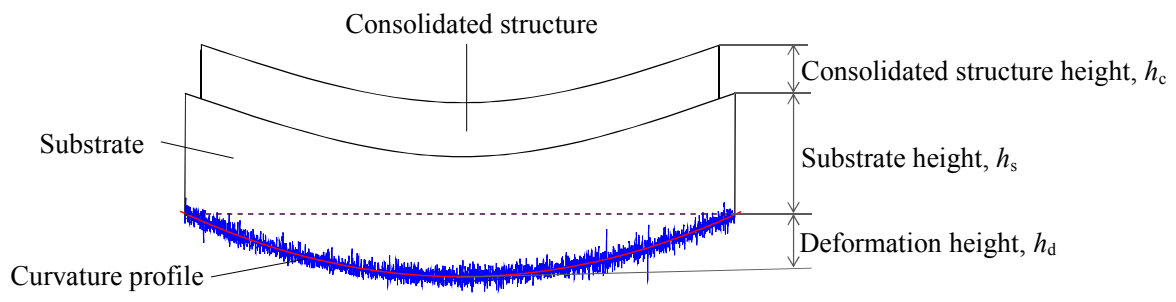

Fig. 5 Measurement of deformation height

Table 6 Measurement conditions of $\mathrm{x}$-ray diffraction

\begin{tabular}{ll}
\hline X-ray optics & ISO-inclination method \\
Radiation & $\mathrm{Cr}-\mathrm{K} \alpha$ \\
Wavelength & $0.229 \mathrm{~nm}$ \\
Filter & $\mathrm{V}$ foil \\
Tube voltage & $30 \mathrm{kV}$ \\
Tube current & $20 \mathrm{~mA}$ \\
Collimator & $\phi 2, \phi 4[\mathrm{~mm}]$ \\
Diffraction line & $\gamma-\mathrm{Fe}(220), \alpha-\mathrm{Fe}(211)$ \\
Fixed time & $60 \mathrm{~s}$ \\
Peak position & $\mathrm{FWHM}$ middle point method \\
\hline
\end{tabular}




\section{Results and discussion}

\subsection{Changes of temperature and stress during laser consolidation process}

The temperature and stress histories of the substrates at specified positions during the laser consolidation process are shown in Fig. 6, and those histories at the $29^{\text {th }}$ and $30^{\text {th }}$ layer are magnified in Fig 7. As indicated in Fig. 6, an increment in temperature and an increment in compressive stress were measured in the first 15 layers of the consolidation process; for each layer, a pair of values representing the increment and decrement in temperature and stress, which are influenced by the laser irradiation, are given.

After the $15^{\text {th }}$ layer, the temperature increment and decrement continue to fluctuate, but the overall temperature is maintained at a constant value. However, it was found that temperature at the edge of the substrate (T1) is about $30^{\circ} \mathrm{C}$ lower than the temperatures at the inner positions (T2 and T3). During this period, stress at the edge of the substrate (S1) is almost constant, but the compressive stresses at the inner positions (S2 and S3) decrease with an increasing number of consolidation layers. The occurrence of a temperature difference between the edge and the inner positions is considered to be the result of the total heat-energy input from laser irradiation and the conduction characteristics of the consolidated structure. For each layer, laser scanning starts near the substrate edge, and therefore, the heat input is small and the temperature at this position is lower than that at the inner positions.

As a result, it can clearly be seen from Fig. 7 that the temperature of $\mathrm{T} 1$ is lower than that of T2 and T3. From this figure, it is found that the temperature and the stress of the substrate are inversely proportional. During laser irradiation, the temperature rises and the irradiated area undergoes thermal expansion. In contrast, the bottom face of the irradiated layer simultaneously shrinks. As soon as the laser moves, the surface of the irradiated area is cooled and shrinks, whereas the bottom face expands. Additionally, a small difference between the stress value at the edge and at the inner positions was also detected.

Referring back to Fig. 6, after the laser consolidation process is finished ( $60^{\text {th }}$ layer), the upper surface of the substrate cools down and the temperature drops to room temperature. Simultaneously, the compressive stress gradually decreases. At this point, when the entire plate reaches room temperature, S3 stress is the highest, followed by S2 and $\mathrm{S} 1$. This result corresponds to the deformation height from the curvature profile of the substrate.

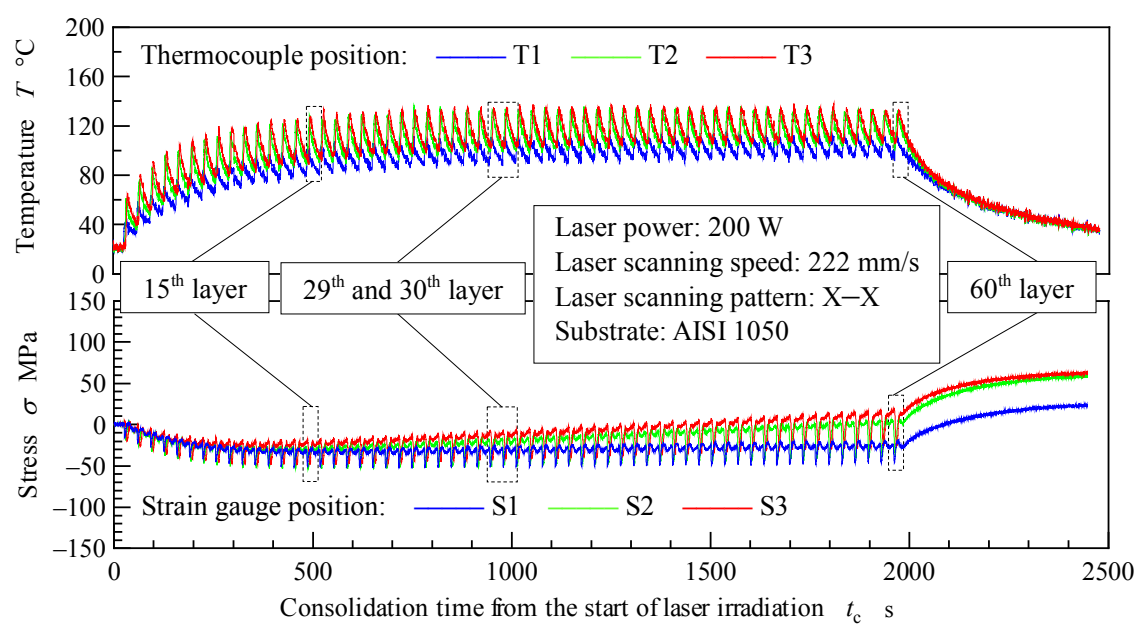

Fig. 6 Temperature and stress histories during the laser consolidation process 


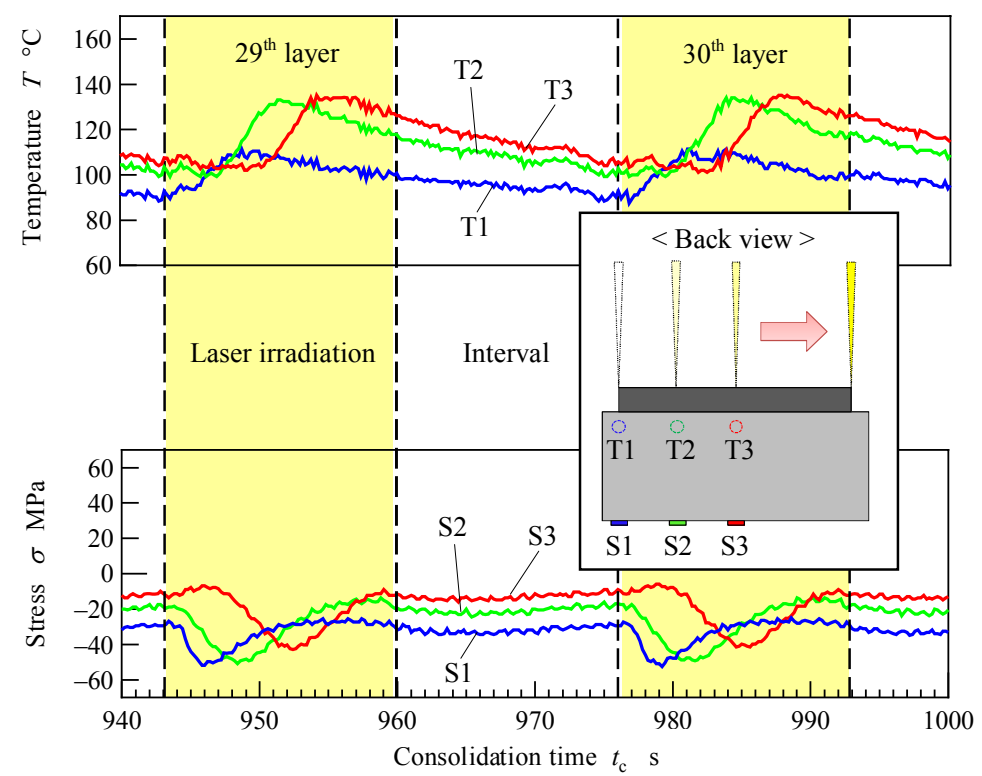

Fig. 7 Temperature and stress histories at the $29^{\text {th }}$ and $30^{\text {th }}$ layers of the laser consolidation process

\subsection{Effects of consolidation conditions on deformation}

Figure 8 shows the measurement of the deformation height when a structure with varied consolidated structure height was fabricated on a $20-\mathrm{mm}$-high carbon steel substrate. As shown in the figure, deformation at the bottom surface of the substrate increases as the consolidated structure height increases. The deformation becomes almost constant when the consolidated structure height exceeds $20 \mathrm{~mm}$. This is because the bending stiffness becomes greater when the consolidated structure height increases. Furthermore, Fig. 9 shows the relationship between the substrate height and the deformation when the consolidated structure height is held constant at $6 \mathrm{~mm}$. From the figure, it is found that the deformation height decreases when the substrate height increases, and the deformation height is about 11 $\mu \mathrm{m}$ when the substrate height is $30 \mathrm{~mm}$. This is also due to the increase in bending stiffness when a thicker substrate is used. However, the occurrence of a small deformation caused by using a thick substrate is affected by the yield stress of the substrate material.

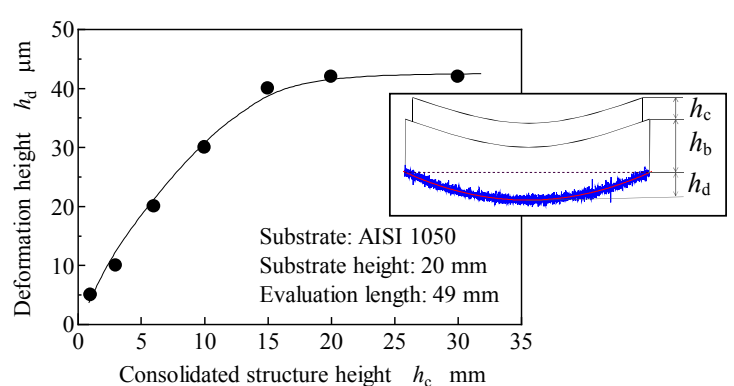

Fig. 8 Influence of consolidated structure height on deformation height

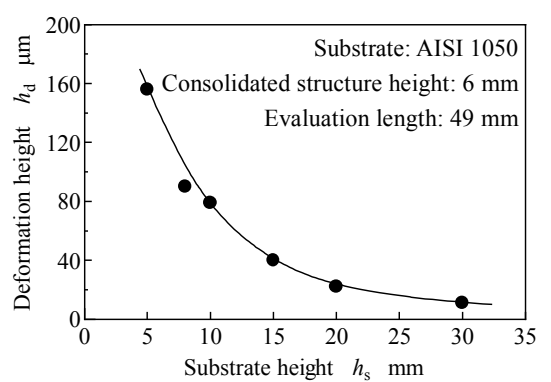

Fig. 9 Influence of substrate height on deformation height

In the layered manufacturing process, a consolidated structure can be obtained by irradiating a laser on the surface of deposited metal powder. The powder is heated by the laser beam and melted, and then the melted powder solidifies when the laser beam moves away from the irradiation area. At this time, the pre-solidified layer is also heated and 
melted, and it mixes with the melted deposited powder within the molten pool ${ }^{(13)}$. Moreover, because the bottom of the molten pool is expanded because of rapid heating during laser irradiation, the consolidation surface softens and exceeds the yield stress; when the laser beam is moved, this surface is rapidly cools and returns to the original state. Through these actions, residual stress is induced at the consolidation surface. This phenomenon is the main factor leading to deformation in the layered manufacturing process.

\subsection{Effects of consolidation conditions on residual stress}

Figures 10 and 11 show the measurements of residual stress at the top surface of the consolidated structure and the bottom face of the substrate at different consolidated structure heights. As shown in Fig. 10, residual stress at the top surface of the consolidated structure increases with respect to the consolidated structure height. Residual stress at the top surface of the substrate increases from 76 to $160 \mathrm{MPa}$ when the consolidated structure height changes from 3 to $12 \mathrm{~mm}$. In contrast, residual stress at the bottom face of the substrate decreases as the consolidated structure height increases. As shown in Fig. 11, the residual stress value decreases from 400 to $290 \mathrm{MPa}$ when the consolidated structure height varies from 3 to $12 \mathrm{~mm}$. Figures 10 and 11 show that the residual stress at the bottom face of the substrate is higher than that of the top surface of the consolidated structure.

In addition, a correlation between the residual stress at the top surface of the consolidated structure and the residual stress at the bottom face of the substrate was discovered. Both figures indicate that the total value of the residual stress at both surfaces is nearly constant for each consolidated structure height. Although the residual stress on the consolidated structure surface is small when the height is low, higher residual stress accumulated at the bottom face of the substrate due to the rapid heating and cooling processes. However, residual stress at the consolidated structure surface also increased when the consolidated structure height increased. Thus, to overcome the stress, residual stress at the bottom face of the substrate decreased. These results indicate that the laser consolidation process on metal powder inevitably generates residual stress within the consolidated structure because of repeated cycles of thermal expansion and shrinkage due to rapid heating and cooling. These effects may also cause deformation. To prevent this problem, it is necessary to select consolidation conditions and a substrate material that can minimize the development of residual stress.

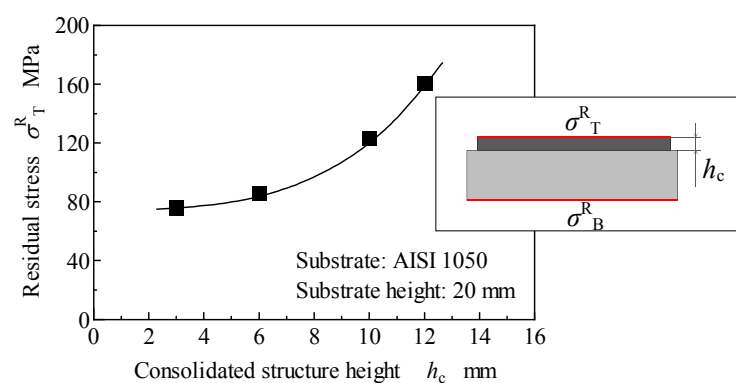

Fig. 10 Residual stress at the top surface of the consolidated structure

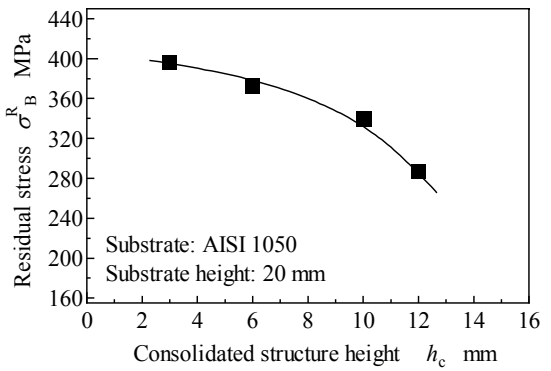

Fig. 11 Residual stress at the bottom face of the substrate

\subsection{Effects of laser scanning patterns on deformation}

The temperature and stress histories of the substrate during the laser consolidation process using different laser scanning patterns are shown in Fig. 12. The temperature histories show that the substrate temperature is higher when performing laser scanning 
along the $\mathrm{y}$-axis $(\mathrm{Y}-\mathrm{Y})$ compared to the $\mathrm{X}-\mathrm{Y}$ and $\mathrm{X}-\mathrm{X}$ patterns. Furthermore, after the completion of the laser consolidation process and the return to the room temperature, the induced stress is highest with the $\mathrm{Y}-\mathrm{Y}$ pattern, followed by the $\mathrm{X}-\mathrm{Y}$ and $\mathrm{X}-\mathrm{X}$ patterns. This result corresponds to the deformation result, which is shown in Fig. 13. The $\mathrm{Y}-\mathrm{Y}$ pattern resulted in the highest deformation $(160 \mu \mathrm{m})$. In contrast, the $X-X$ pattern, which had the smallest stress at the end of the laser consolidation process, produced the smallest deformation compared to the scanning patterns of $\mathrm{Y}-\mathrm{Y}$ and $\mathrm{X}-\mathrm{Y}$. These results are in accordance with the consolidation plane shape used in this research, which is a rectangle. Therefore, in this case, laser scanning a sector along its width induced lower temperature and stress, and led to less deformation.

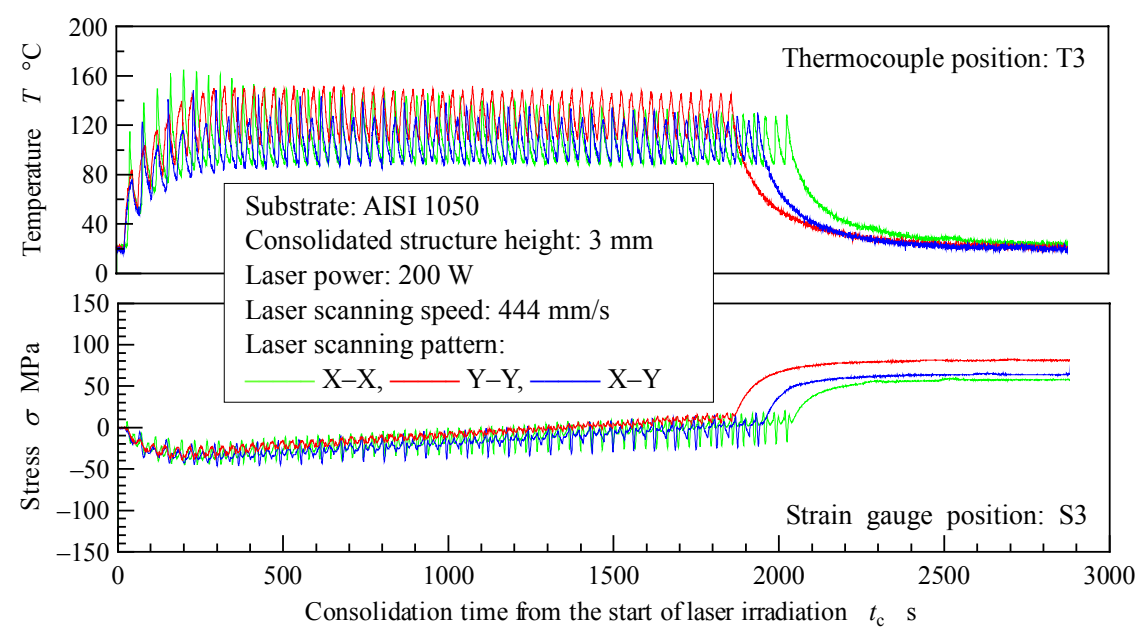

Fig. 12 Temperature and stress histories of different laser scanning patterns

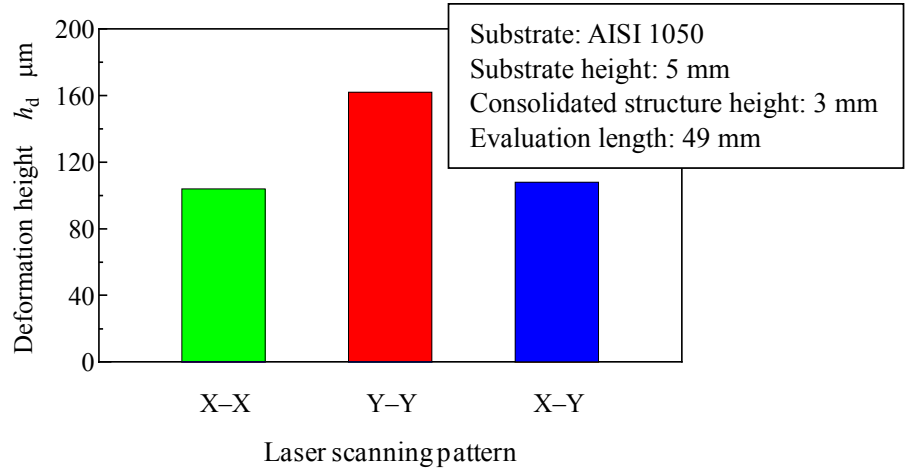

Fig. 13 Influence of laser scanning pattern on deformation

\subsection{Effects of substrate material on deformation}

To investigate the effect of substrate material on deformation, carbon steel (AISI 1050) and stainless steel (AISI 304) were used as the substrate during the laser consolidation process. The temperature of the substrate was monitored using a thermocouple inserted into the substrate at a point $2 \mathrm{~mm}$ from the top surface, and the stress produced in the substrate was measured using a strain gauge, which was attached at the bottom face. The temperature and stress histories during the laser consolidation process are shown in Fig. 14. Consolidation conditions used in this experiment were the same as shown in Table 1, except that the laser scanning speed was set at $222 \mathrm{~mm} / \mathrm{s}$ to achieve a higher laser-energy density because the consolidated structure was not well fused with the stainless steel substrate at a low energy density. The substrate height and the consolidated structure height used were 20 
and $3 \mathrm{~mm}$, respectively. During the laser consolidation process, it was found the expansion and shrinkage of the stainless steel substrate changed drastically compared to that of the carbon steel substrate. This was because the linear expansion coefficient of stainless steel is about 1.5 times that of carbon steel. The temperature variation in both substrates follows the same pattern, which was described in $\$ 4.1$. It was found that the temperature was higher with stainless steel as the substrate than it was with carbon steel as the substrate, even under the same consolidation conditions. The average temperature difference between both substrates was about $50{ }^{\circ} \mathrm{C}$. This result was influenced by the thermal conductivity of the substrate materials. The thermal conductivity of stainless steel is about $1 / 3$ that of carbon steel; material with lower thermal conductivity will produce a higher temperature because it is difficult to conduct heat around it. The temperature of each layer irradiated by the laser beam during the laser consolidation process is almost constant ${ }^{(7)}$. As the number of consolidation layers is increased, the entire part is heated, which could cause a smaller temperature difference between the irradiated layer and the stainless steel substrate compared to the temperature difference between the irradiated layer and the carbon steel substrate. After the laser consolidation process is completed and the substrate reaches room temperature, the stress becomes constant; in the stainless steel substrate, the stress value was lower than it was in the carbon steel substrate. This result corresponds to the deformation result shown in Fig. 15. The laser consolidation process using carbon steel as the substrate resulted in a deformation height of $158 \mu \mathrm{m}$, whereas the deformation was 99 $\mu \mathrm{m}$ for the stainless steel substrate. Therefore, utilization of stainless steel as the substrate can reduce deformation by about $40 \%$ compared to carbon steel.

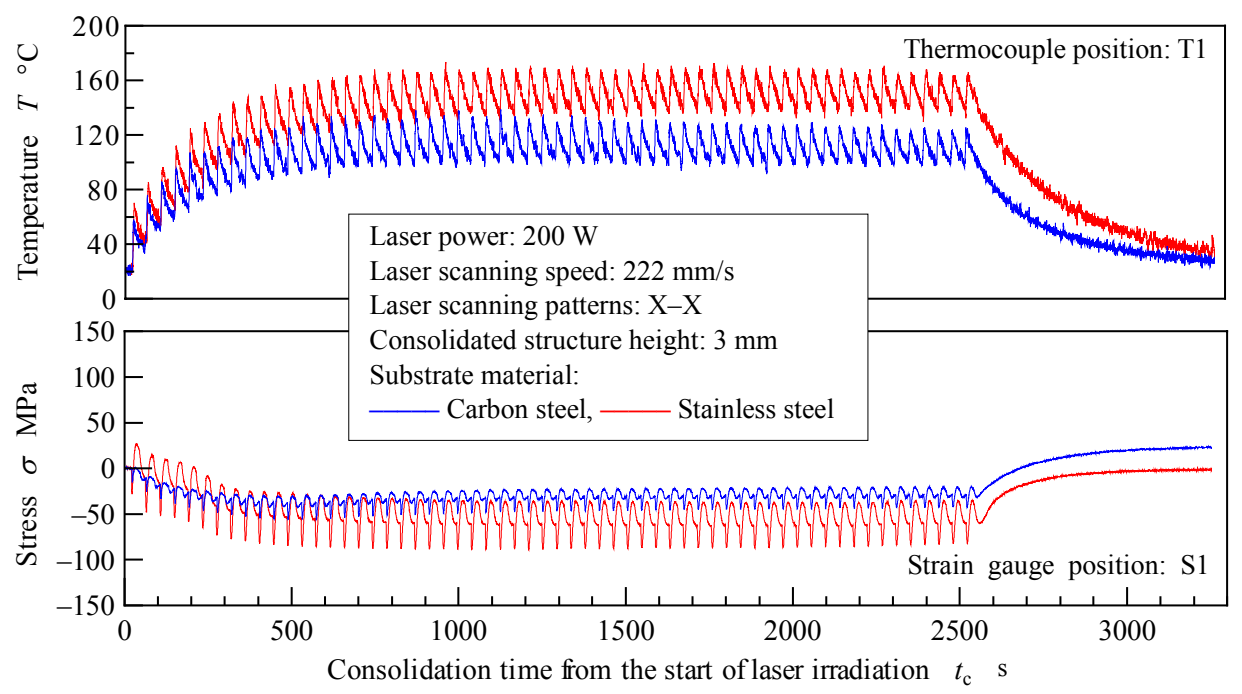

Fig. 14 Temperature and stress histories during the laser consolidation process using different substrate materials

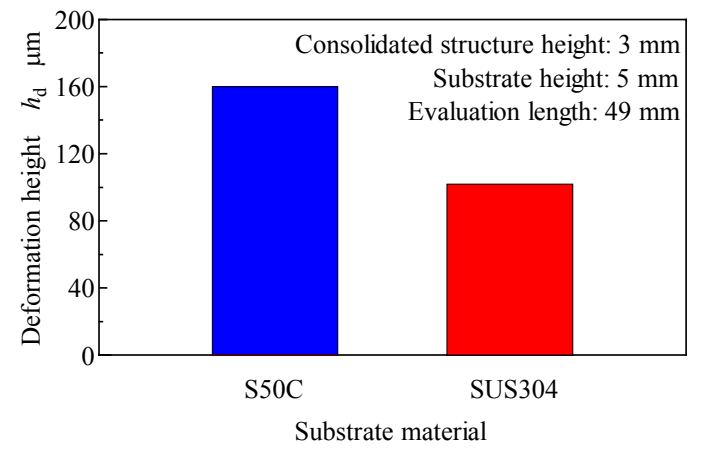

Fig. 15 Influence of different substrate materials on deformation 


\section{Conclusions}

Residual stress development within a consolidated structure and the reduction of residual stress were experimentally investigated. The results can be summarized as follows:

1. During the laser consolidation process, the temperature change in the substrate causes repeated thermal expansion and shrinkage within the substrate, which results in internal stress after the process is complete. The induced stress corresponds to the substrate deformation.

2. Deformation of the consolidated structure increases with respect to the consolidated structure height and becomes constant at a certain height, whereas it decreases as the substrate height increases. These results were influenced by the bending stiffness, and the yield strength of the substrate is almost constant.

3. Residual stress at the top surface of the consolidated structure increases whereas residual stress at the bottom face of the substrate decreases as the consolidated structure height increases.

4. Laser scanning of a sector along the width induces less stress after the completion of the laser consolidation process, leading to less deformation.

5. Less deformation occurs using stainless steel as the substrate in the laser consolidation process than when using carbon steel as the substrate. This is due to the different thermal conductivities and linear expansion coefficients of the materials used as the substrate.

\section{Acknowledgement}

The authors would like to express their sincere gratitude to Panasonic Corporation Eco Solutions Company for providing layered manufacturing equipment, their support and precious advice.

\section{References}

(1) Kimura, F. and Suzuki, H., A CAD system for efficient product design based on design intent, CIRP Annals - Manufacturing Technology, Vol.38, No.1(1989), pp.149-152.

(2) Lin B. T. and Kuo C. C., Application of an integrated CAD/CAM/CAE system for stamping dies for automobiles, International Journal of Advanced Manufacturing Technology, Vol.35, No.9-10(2008), pp.1000-1013.

(3) Kodama, H., Automatic method for fabricating a three-dimensional plastic model with photo-hardening polymer, Review of Scientific Instruments, Vol.52, No.11(1981), pp.1770-1773.

(4) Kruth, J. P., Material Incress Manufacturing by Rapid Prototyping Techniques, CIRP Annals - Manufacturing Technology, Vol.40, No.2(1991), pp.603-614.

(5) Kruth J.-P., Levy G., Klocke F. and Childs T.H.C., Consolidation phenomena in laser and powder-bed based layered manufacturing, CIRP Annals - Manufacturing Technology, Vol.56, No.2(2007), pp.730-759.

(6) Abe, S., Higashi, Y., Fuwa, I., Yoshida, N. and Yoneyama, T., Milling-combined laser metal sintering system and production of injection molds with sophisticated functions, 11th International Conference of Precision and Engineering, ICPE2006, (2006), pp. 288-293.

(7) Furumoto, T., Ueda, T., Kobayashi, N., Yassin, A., Hosokawa, A. and Abe, S., Study on laser consolidation of metal powder with Yb:fiber laser - Evaluation of line consolidation structure, Journal of Materials Processing Technology, Vol.209, No.18-19(2009), pp.5973-5980.

(8) Shiomi, M., Osakada, K., Nakamura, K., Yamashita, T. and Abe, F., Residual stress within 
metallic model made by selective laser melting process, CIRP Annals - Manufacturing Technology, Vo.53, No.1(2004), pp.195-198.

(9) Mercelis, P. and Kruth, J. P., Residual stresses in selective laser sintering and selective laser melting, Rapid Prototyping Journal, Vol.12, No.5(2006), pp.254-265.

(10) Furumoto, T., Ueda, T., Abdul Aziz, M.S., Hosokawa, A. and Tanaka, R., Study on reduction of residual stress induced during rapid tooling process: Influence of heating conditions on residual stress, Key Engineering Materials, Vol.447-448(2010), pp.785-789.

(11) Yasa, E., Deckers, J., Kruth, J.P., Rombouts, M. and Luyten, J., Investigation of sectoral scanning in selective laser melting, ASME 2010 10th Biennial Conference on Engineering Systems Design and Analysis, ESDA2010, Vol.4(2010), pp.695-703.

(12) Aziz, M.S.A., Furumoto, T., Ueda, T., Abe, S., Hosokawa, A. and Tanaka, R., Study on thermal and strain behaviour in selective laser sintering process, Key Engineering Materials, Vol.516(2012), pp.203-208.

(13) Furumoto, T., Ueda, T., Hosokawa, A., Yassin, A. and Abe, S., Study on the sintering characteristics of the mixed metal powder with $\mathrm{Yb}$ fiber laser - Evaluation of the adhesion force of the sintered material on the different surface plate, Seimitsu Kogaku Kaishi/Journal of the Japan Society for Precision Engineering, Vol.74, No.8(2008), pp.836-840.

(14) Furumoto, T., Ueda, T., Hosokawa, A., Abe, S. and Childs, T.H.C., Study on the measurement of physical properties in the metal powder for rapid prototyping - Proposal of measurement of thermal conductivity and absorption of laser beam. Journal of the Japan Society for Precision Engineering, Vol.73(2007), pp.558-562.

(15) Yassin, A., Ueda, T., Furumoto, T., Hosokawa, A., Tanaka, R. and Abe, S., Experimental investigation on cutting mechanism of laser sintered material using small ball end mill, Journal of Materials Processing Technology, Vol.209, No.15-16(2009), pp.5680-5689.

(16) Miyano, M., Sasaki, T., Takago, S. and Hirose, Y., A fundamental study on X-Ray stress measurement of sintered FeCr/TiN composite material, Nihon Kikai Gakkai Ronbunshu, A Hen/Transactions of the Japan Society of Mechanical Engineers, Part A, Vol.64, No.617(1998), pp.200-208. 